\title{
Neumonía complicada con neumatocele en un lactante, caso clínico
}

\author{
BERNARDITA CHATEAU I. ${ }^{1}$, CAROLINA ARAVENA P. ${ }^{2}$, FERNANDO VULETIN $\mathrm{S}^{3}{ }^{3}$, \\ CRISTIAN GARCÍA B. ${ }^{4}$, SERGIO ZÚÑIGA R. ${ }^{5}$, NILS HOLMGREN P. ${ }^{6}$ \\ 1. Pediatra Broncopulmonar, Hospital Josefina Martínez. \\ 2. Interna de Medicina, Facultad de Medicina, Pontificia Universidad Católica de Chile. \\ 3. Cirujano Infantil, División de Cirugía, Sección de Cirugía Pediátrica, Facultad de Medicina, Pontificia Universidad Católica \\ de Chile. \\ 4. Radiólogo, Profesor Titular, Departamentos de Radiología y Pediatría, Facultad de Medicina, Pontificia Universidad Católica \\ de Chile. \\ 5. Cirujano Infantil, Profesor Adjunto, División de Cirugía, Sección de Cirugía Pediátrica, Facultad de Medicina, Pontificia \\ Universidad Católica de Chile. \\ 6. Pediatra Broncopulmonar, Profesor Auxiliar, Departamento de Pediatría, Facultad de Medicina, Pontificia Universidad \\ Católica de Chile.
}

\begin{abstract}
Complicated Pneumonia with Pneumatocele in a infant: Case-report

Introduction: Pneumatocele is an uncommon complication of pneumonia, most often asymptomatic with spontaneous resolution. Case-report: Female infant with an history of right upper lobe pneumonia, an air filled structure was noted in the chest X-ray. Asymptomatic until admitted for a wheezing episode, where an increase in the size of the structure was evidenced. She had clinical and radiological follow-up as recommended in a recent study, observing that 5 months later the cystic image was completely resolved. Discussion: According to criteria from published studies, this case is a non complicated pneumatocele because it was asymptomatic, compromised less than $50 \%$ of the hemithorax and no atelectasia, bronchopleural fistula or signs of infection were observed. Non complicated pneumatoceles can be followed up, and complicated can be treated by image guided catheter drainage or surgical resection. In this case, we confirmed spontaneous resolution after clinical and radiological follow-up.

(Key words: Pneumonia, infant, complication, peumatocele)

Rev Chil Pediatr 2008; 79 (3): 295-300
\end{abstract}

\section{RESUMEN}

Introducción: El neumatocele es una complicación poco frecuente de la neumonía, generalmente asintomático que se resuelve espontáneamente. Objetivo: Describir la presentación clínica e imageneológica de un neumatocele en un paciente pediátrico. Caso Clínico: Lactante mayor, género femenino, con antecedente

Trabajo recibido el 28 de diciembre de 2006, devuelto para corregir el 19 de marzo de 2007, segunda versión el 12 de marzo de 2008, aceptado para publicación el 09 de abril de 2008.

Correspondencia a:

Bernardita Chateau I.

E-mail: bernarditachateau@gmail.com 
de neumonía del lóbulo superior derecho a los 16 meses de vida. En controles radiográficos posteriores se evidenció una imagen aérea de paredes finas en ápex derecho en progresivo aumento. Asintomática hasta los 20 meses cuando fue hospitalizada por cuadro bronquial obstructivo por virus respiratorio sincicial y se constató crecimiento de la imagen. Se tomó conducta expectante manteniendo seguimiento clínico y radiológico. A la edad de 21 meses se evidenció resolución casi completa de imagen radiográfica. Conclusión: Este caso corresponde a un neumatocele simple, donde se recomienda mantener bajo observación. Los complicados pueden ser drenados por punción bajo imagen radiológica o resecados quirúrgicamente. En este caso se optó por seguimiento clínico y radiológico, pudiendo confirmar su resolución espontánea en el estudio posterior.

(Palabras clave: Neumonía, lactante, complicación, neumatocele).

Rev Chil Pediatr 2008; 79 (3): 295-300

\section{Introducción}

La neumonía es una de las patologías más frecuentes de la infancia y en un porcentaje considerable se presentan complicaciones, las que son responsables de gran parte de las hospitalizaciones por esta causa y prolongan la estadía y la recuperación. El neumatocele es una complicación poco reportada de la neumonía ${ }^{1}$. Es una formación adquirida de contenido aéreo de paredes delgadas formadas por el parénquima pulmonar adyacente. La evolución clínica es en general favorable, aunque en un porcentaje pueden, a su vez, complicarse con ruptura o infección ${ }^{2}$.

El objetivo de la presente comunicación es describir la presentación clínica e imagenes de un neumatocele en un paciente pediátrico, así como discutir las variantes clínicas, potenciales complicaciones y las eventuales terapias que deben plantearse ante esta complicación, basado en la experiencia local y lo publicado internacionalmente.

En la literatura nacional y extranjera existen pocos reportes de esta complicación. El reporte de la serie más grande de esta situación en niños fue realizado en Turquía; propone criterios para clasificar y un flujograma de conducta que fueron usados en este caso en particular ${ }^{3}$.

\section{Caso clínico}

Se trata de una lactante menor, con antecedentes de un cuadro bronquial obstructivo a los 10 meses de vida, con estudio radiológico que mostró escasas imágenes intersticiales, sin otros hallazgos. No refirió otros antecedentes mórbidos. La paciente se mantuvo en buenas condiciones hasta los 16 meses de edad, cuando fue hospitalizada por una neumonía adquirida en la comunidad del lóbulo superior derecho (figura 1). Recibió tratamiento antibiótico endovenoso (Cefotaxima), evolucionando satisfactoriamente con resolución completa del cuadro clínico. Quince días más tarde se controló radiografía de tórax, en la cual se evidenció una imagen aérea redondeada de paredes finas en el ápex pulmonar derecho (figura 2), la cual aumentó de tamaño en los controles radiográficos posteriores (figura 3), permaneciendo la paciente absolutamente asintomática. A los 20 meses de

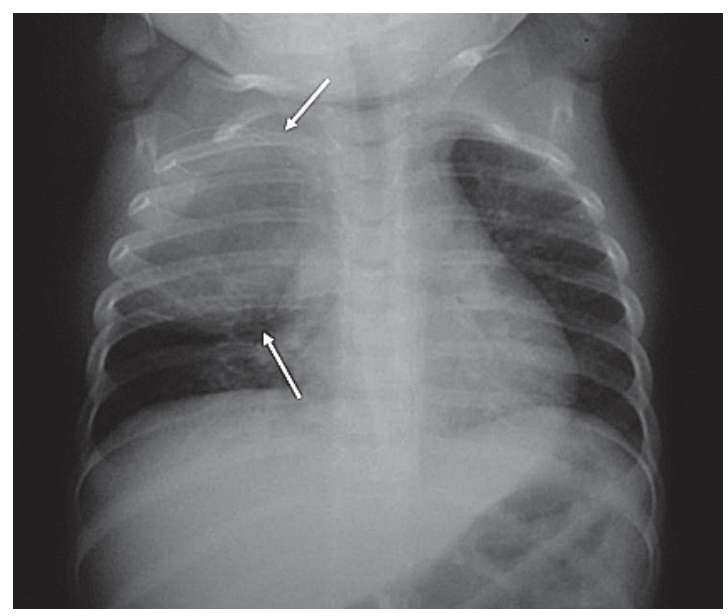

Figura 1. Neumonía lóbulo superior derecho, 16 meses de edad. 
edad fue hospitalizada por un cuadro bronquial obstructivo por virus respiratorio sincicial y probable sobreinfección bacteriana caracterizado por fiebre, polipnea y sibilancias. En esta oportunidad la radiografia de tórax evidenció imágenes intersticiales bilaterales y crecimiento de la imagen descrita desde el último control. La paciente fue derivada a nuestro centro en este momento y se confirmó el diagnóstico de neumatocele con tomografía axial computada de tórax (figura 4). Presentó respuesta favorable

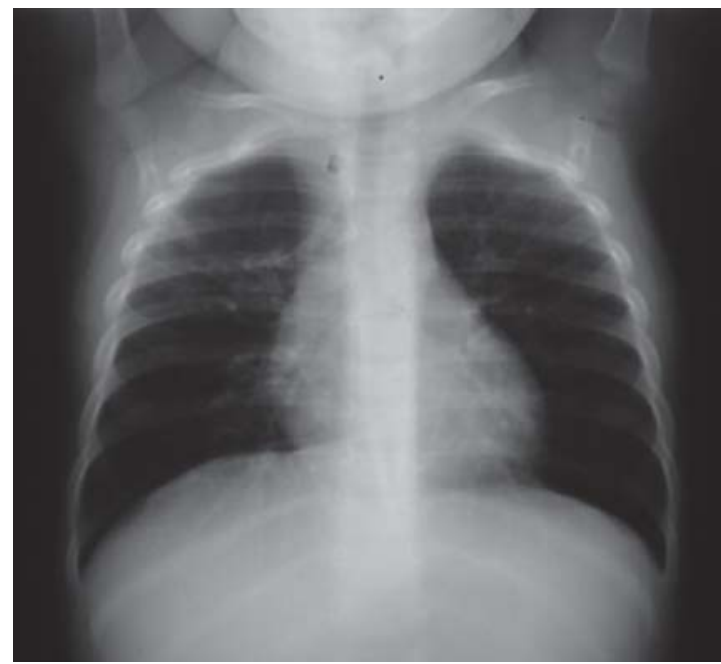

Figura 2. Aparición de imagen quística lóbulo superior derecho, 17 meses de edad.

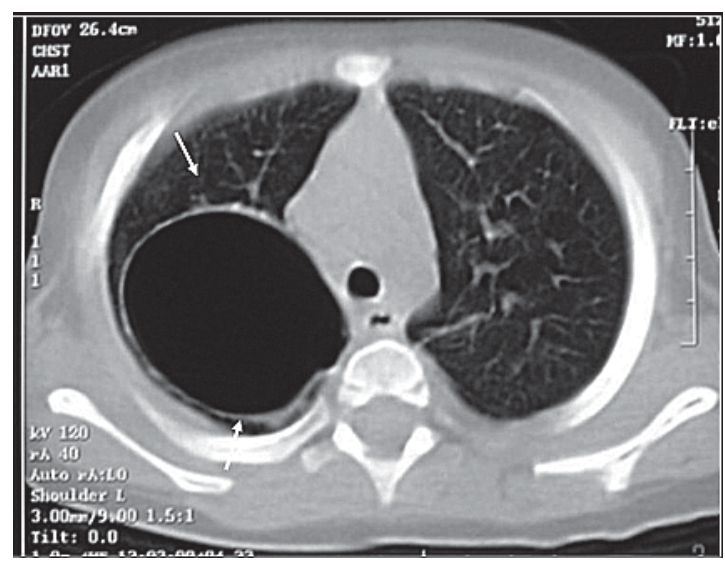

Figura 4. TAC tórax, 20 meses de edad. al aporte de oxígeno y los broncodilatadores, cediendo los síntomas respiratorios en 3 días. Dado el estado clínico de la paciente se adoptó conducta expectante en cuanto al neumatocele, con seguimiento clínico y radiológico. Una vez resuelto su cuadro respiratorio intercurrente fue dada de alta en buenas condiciones. La paciente se mantuvo asintomática $\mathrm{y}$ en el control radiológico de los 21 meses de edad se observó resolución completa de la imagen pulmonar (figura 5).

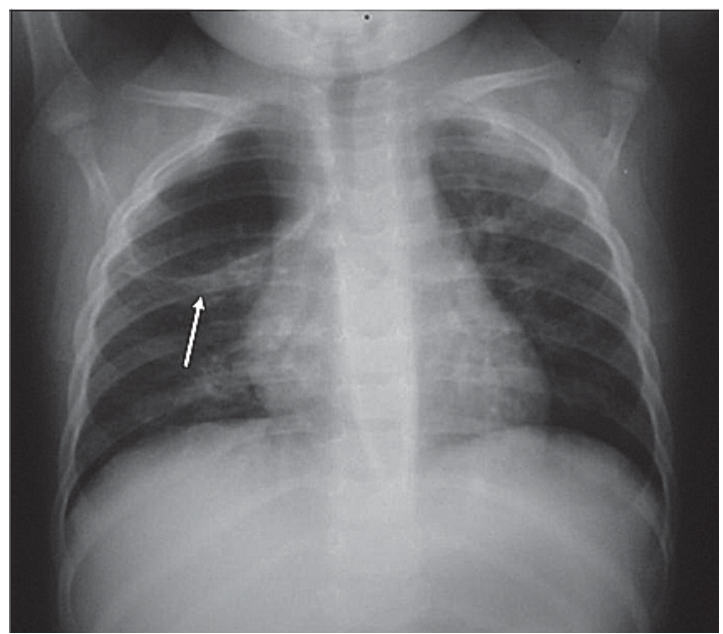

Figura 3. Controles radiológicos a los 18 meses de edad. Se evidencia aumento tamaño imagen quística.

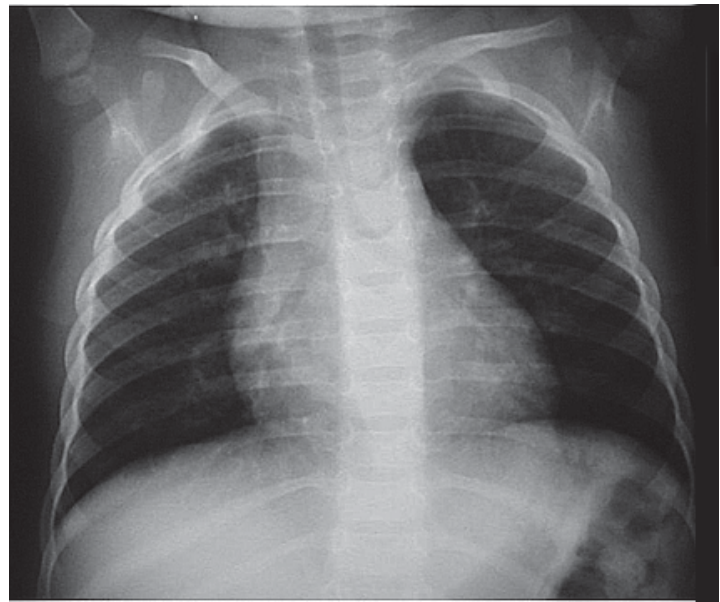

Figura 5. Control, 21 meses de edad. 


\section{Discusión}

No es infrecuente que los niños presenten complicaciones durante la evolución de una neumonía, como derrame pleural, empiema, atelectasias, neumotórax y neumatocele. La aparición de complicaciones en el curso de una neumonía está relacionada con factores del huésped y del agente etiológico ${ }^{1}$.

Los neumatoceles pulmonares son formaciones adquiridas, de contenido aéreo y paredes finas que se desarrollan en el intersticio pulmonar después de una injuria o inflamación del parénquima. Durante el proceso de una neumonía bacteriana, el neumatocele se desarrolla como resultado de necrosis alveolar y bronquiolar localizada, permitiendo el paso de aire en una sola dirección, hacia el espacio intersticial, dando como resultado la formación espacios intraparenquimatosos llenos de aire, los cuales pueden ser únicos o múltiples ${ }^{2,3}$.

La incidencia reportada de esta complicación es variable. Se estima una incidencia general de $2-3 \%$ de todas las neumonías, llegando a $8,3 \%$ y $9,5 \%$ en estudios retrospectivos de población pediátrica hospitalizada por neumonía, realizados en Brasil y Nigeria respectivamente ${ }^{1,4}$.

El neumatocele es una posible complicación de neumonías de distinta etiología infecciosa. Dentro de los agentes bacterianos el Staphylococcus aureus es el agente etiológico más comúnmente descrito. Otras agentes infecciosos descritos son: Streptococcus pneumoniae, Haemophilus influenzae, Escherichia coli, Streptococcus grupo A, Klebsiella pneumoniae, Pneumocystis jirovecci, Adenovirus y tuberculosis ${ }^{1,3-6}$. Se han descrito causas no infecciosas, como el trauma, la inhalación de cáusticos e hidrocarburos y la ventilación a presión positiva ${ }^{7,8}$.

El diagnóstico de neumatocele es por imágenes. La radiografía de tórax simple en una o dos proyecciones es de gran utilidad, pero no tiene la sensibilidad suficiente para evaluar en detalle tamaño, la estructura de la pared y relaciones anatómicas de la lesión. La tomografía axial computada de tórax puede establecer el diagnóstico definitivo. Esto es importante para el diagnóstico diferencial con neumotórax, que puede también presentarse en el curso de una neumonía. El neumatocele se observa como una lesión redondeada llena de aire, intraparenquimatosa, en contraste con el neumotórax, donde se observa colección de aire en el espacio pleural ${ }^{3}$.

El neumatocele postinfeccioso generalmente aparece dentro de las primeras dos semanas de evolución de la neumonía. En el caso presentado fue detectado quince días luego de una neumonía condensante. En la mayoría de los casos los neumatoceles son asintomáticos y se resuelven espontáneamente en un promedio de 6 semanas, sin dejar secuelas y sin necesidad de resolución quirúrgica. Sin embargo, se han descrito casos en que este proceso es más largo y la regresión de la lesión puede demorar meses o más en desaparecer ${ }^{4,9,10}$. Así es como en esta paciente se observó una resolución total después de casi 5 meses de evolución.

Aunque la mayoría de los neumatoceles regresan con la mejoría de la enfermedad subyacente, ocasionalmente, pueden complicarse. Una de las complicaciones más frecuentes es la sobreinfección ya que esta estructura aérea representa un espacio fácil para la llegada y el desarrollo bacteriano.

Otra complicación importante es el aumento de volumen con formación de neumatoceles a tensión y la ruptura al espacio pleural. Esto se produce como consecuencia del mecanismo de válvula y atrapamiento aéreo continuo, y se ha descrito en asociación al uso de ventilación a presión positiva. Como consecuencia, puede haber formación de fístula broncopleural, colapso pulmonar, compresión de estructuras adyacentes, obstrucción de vía aérea e inestabilidad cardiorrespiratoria, requiriendo en casos extremos descompresión urgente ${ }^{9,11}$. Aunque es poco común, la ruptura pudiera producirse después del alta, por lo que es muy importante ser extremadamente cuidadosos en el seguimiento de neumatoceles grandes. Dada la favorable evolución en la mayoría de los casos, la mayor parte de los autores sugieren que el manejo debe ser conservador, con tratamiento antibiótico de la neumonía y seguimiento clínico y radiológico cuidadoso ${ }^{3}$.

Intentando estandarizar el manejo de esta complicación, Imamoglu et al, reportan 58 ca- 


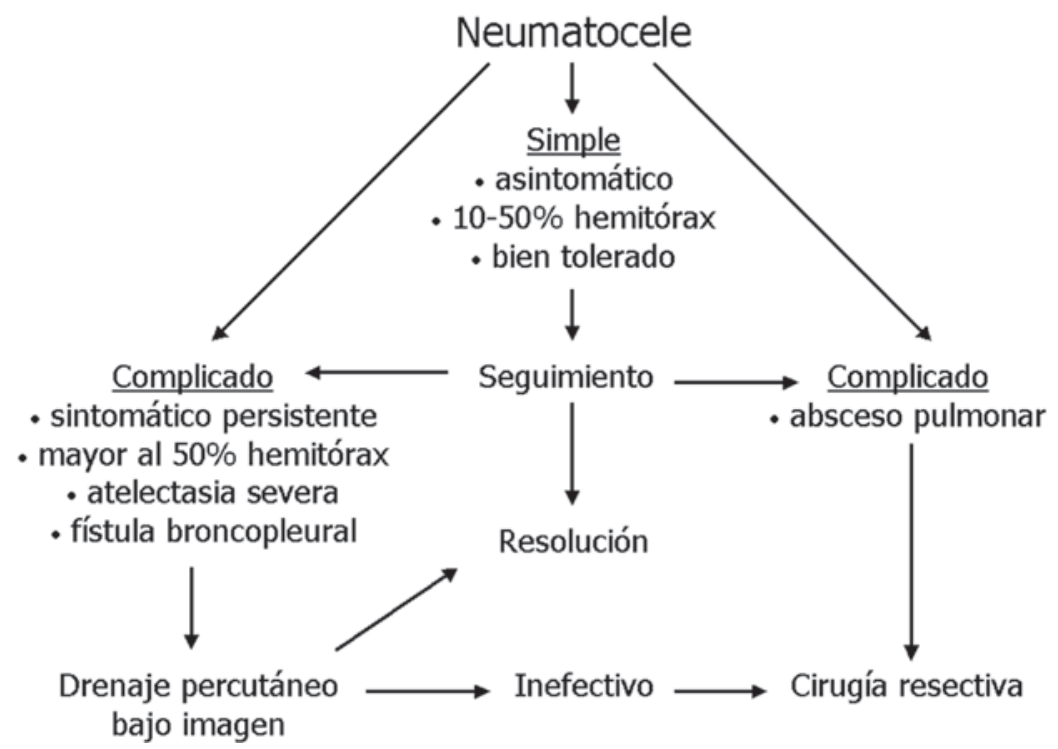

Figura 6. Algoritmo de tratamiento para neumatocele. (Adaptado J Pediatr Surg 2005; 40: 1111-7).

sos de neumatocele en niños con características y evolución variables y los clasifican en neumatoceles simples y complicados. Los neumatoceles simples son aquellos asintomáticos, con buena tolerancia al seguimiento, cuyo tamaño no compromete más del $50 \%$ del hemitórax y que no están asociados a atelectasia. Los neumatoceles complicados son aquellos que presentan una o más de las siguientes características: signos persistentes de dificultad respiratoria, tos y taquipnea, signos de infección, tamaño mayor del 50\% del hemitórax, asociados a atelectasia persistente, o fístula broncopleural, que no disminuyen de tamaño o engrosamiento de la pared durante el seguimiento de 6 meses $^{3}$. Estos mismos autores proponen un algoritmo de conducta, en el que los neumatoceles simples son seguidos clínicamente hasta su resolución completa y para los neumatoceles complicados se recomienda drenaje por punción percutánea guiada por imágenes. Si este tratamiento es inefectivo o el neumatocele complicado se presenta como gran absceso o es persistente con engrosamiento de la pared, se recomienda ir directamente a cirugía $^{3}$ (figura 6).

Aunque esta clasificación no ha sido valida$\mathrm{da}$, es una buena aproximación a la definición y tratamiento exitoso de los neumatoceles, identi- ficando y diferenciando los grupos de pacientes que se beneficiarán de drenaje percutáneo o de cirugía, de aquellos que evolucionarán bien sólo con seguimiento cercano. Esta selección debe ser hecha basada en las características clínicas y radiológicas del paciente.

En el caso presentado, las características radiológicas, la buena tolerancia al seguimiento clínico permitió catalogarlo como neumatocele simple de acuerdo a la clasificación anteriormente mencionada, determinando una conducta conservadora. La evolución final fue satisfactoria, mostrando resolución completa en el seguimiento.

En conclusión, el neumatocele es una complicación probable de una neumonía. Aunque su presentación en general es asintomática y evoluciona hacia la resolución espontánea, puede presentar complicaciones, por lo que la evaluación detallada y el seguimiento clínico y radiológico estricto es requerida.

\section{Referencias}

1.- Wexler ID, Knoll S, Picard E, et al: Clinical characteristics and outcome of complicated pneumococcal pneumonia in a pediatric population. Pediatr Pulmonol 2006; 41: 726-34. 
2.- Quigley $M J$, Fraser RS: Pulmonary pneumatocele: pathology and pathogenesis. Am J Roentgenol 1988; 150: $1275-7$.

3.- Imamoglu M, Cay A, Kosucu P, et al: Pneumatoceles in postpneumonic empyema: an algorithmic approach. J Pediatr Surg 2005; 40: 1111-7.

4.- Kunyoshi V, Cataneo DC, Cataneo AJ: Complicated pneumonias with empyema and/or pneumatocele in children. Pediatr Surg Int 2006; 22: 186-90

5.- Amitai I, Mogle P, Godfrey S, Aviad I: Pneumatocele in infants and children. Report of 12 cases. Clin Pediatr (Phila) 1983; 22: 420-2.

6.- Asmar BI, Thirummoothi MC, Dajani AS: Pneumococcal pneumonia with pneumatocele formation. Am J Dis Child 1978; 132: 1091-3.
7.- Schimpl G, Schneider U: Traumatic pneumatoceles in an infant: case report and review of the literature. Eur J Pediatr Surg 1996; 6: 104-6.

8.- Bray A, Pirronti T, Marano P: Pneumatoceles following hydrocarbon aspiration. Eur Radiol 1998; 8: 262-3.

9.- Wu ET, Chen JS: Management of multiple tension pneumatoceles refractory to tube thoracostomy decompression. Ann Thorac Surg 2006; 81: 1482-4.

10.- Victoria MS, Steiner P, Rao M: Persistent postpneumonic pneumatoceles in children. Chest 1981; 79: 359-61.

11.- Shen HN, Lu FL, Wu HD, Yu CJ, Yang PC: Management of tension pneumatocele with high frequency oscillatory ventilation. Chest 2002; 121: 284-6. 